\title{
El cara a cara con el otro: la visión de lo ajeno a fines de la Edad Media y comien- zos de la Edad Moderna a través del viaje
}

Autor: Pedro Martínez García.

Director: Juan Carlos Martín Cea

Defendida en el Departamento de Historia Antigua y Medieval, Facultad de Filosofia y Letras, Universidad de Valladolid, julio de 2014.

Calificación: sobresaliente cum laude

\section{RESUMEN:}

Este trabajo es un estudio sobre la alteridad y sobre la identidad desde finales de la Edad Media hasta comienzos de la expansión colonial atlántica en la Edad Moderna. Son muchos los relatos de viaje medievales en los que el lector es confrontado con descripciones familiares y con lugares comunes que conforman una suerte de horizonte epistémico entre el redactor del relato y el receptor del mismo. Un ejemplo ilustrativo es la clásica descripción de las ciudades y de las regiones visitadas por el viajero, en muchos casos descritas a través de modelos retóricos como el Laudibus Urbium. De esta manera ciudades como Roma o Jerusalén son presentadas en el siglo $\mathrm{XV}$ de manera similar a como se presentarían hoy Nueva York o Tokio, mil veces vistas y conocidas de antemano incluso antes de haberlas pisado. ¿Cuál sería entonces la impresión del viajero medieval al confrontarse con algo radicalmente nuevo? ¿Serían las sensaciones de los primeros pilotos europeos en América muy diferentes a las de cualquiera que hoy tuviera que explorar el lado oculto de la luna o la superficie de un nuevo planeta?

Esta duda deriva en una de las preguntas centrales del proyecto: ¿cómo describe el viajero al otro totalmente desconocido en comparación al extraño ya conocido o del que al menos se tienen referencias? A medida que el trabajo se va desarrollando, esta pregunta dará pie a otra: ¿hay verdaderamente un otro desconocido para el viajero en el llamado "Nuevo Mundo"? La cuestión de la alteridad en el relato de viajes deriva en varias preguntas más concretas: ¿es el otro diverso y heterogéneo, o se percibe al extranjero como un individuo perteneciente a un colectivo homogéneo?, ¿qué diferencias hay entre las descripciones de los viajeros medievales y las de los primeros exploradores atlánticos? y ¿cuál es la influencia de la cosmovisión medieval en la forma de ver al otro americano en los primeros relatos de la conquista?

Para contestar estos interrogantes se ha trabajado sobre varios relatos de viaje del occidente medieval, presentando en cada caso el contexto sociopolítico y cultural de cada uno de los viajeros y analizando las diferentes voces contenidas en las fuentes. Todos los relatos utilizados en este proyecto están basados en auténticos contactos con gentes extrañas en tierras distantes a las propias ocurridos entre los siglos XV y XVI. El trabajo discurre por tanto entre lo que tradicionalmente se ha entendido como la baja Edad Media y los comienzos de la modernidad.

Se han seleccionado las fuentes por su interés para el estudio de la alteridad, en estos relatos la descripción de personas diferentes y de culturas ajenas son particularmente ricas y representativas de la época y del espacio analizado. Naturalmente el 
interés por el otro varía según el contexto del viaje, no es lo mismo la percepción de un embajador castellano del siglo XV en Samarcanda que la de un soldado alemán en los territorios tupís del siglo XVI. Lo que es común a todos los relatos es una ubicación ética y epistémica común; es evidente que todos los viajeros analizados tienen formas de ver la vida y personalidades diferentes entre sí, pero aún con estas obvias desigualdades, todos comparten su pertenencia a un mundo entrelazado, con un discurso greco-latino-cristiano afin.

Este trabajo se centra por tanto en la visión que unos, los viajeros del occidente tardo medieval y comienzos de la Edad Moderna, tienen sobre otras personas que encuentran a lo largo del camino; en cómo ve el que se desplaza al que permanece estático, cómo se describe la periferia mediterránea medieval y cómo se describe la periferia atlántica antes del surgimiento del pensamiento colonial moderno.

Naturalmente los asuntos de la otredad nunca son sencillos, y la identidad varía según sea la mirada del que describe. Así que esta aparente homogeneidad cultural compartida por los viajeros del occidente medieval ha sido interrogada en cada caso, para revelar las reflexiones particulares de cada uno de ellos.

Desde el punto de vista estructural la tesis está dividida en dos bloques fundamentales. El primer bloque está dividido en tres Capítulos principales. El primero de ellos está dedicado al estudios del viaje y de la movilidad en la Edad Media, ilustrando los destinos más habituales y repasando las causas que motivaban el desplazamiento. Se ha recurrido para ello a fuentes muy variadas, desde la Embajada a Tamorlán de Ruy González de Clavijo a métodos de idiomas de mediados del siglo XV como el diccionario de Georg von Nürnberg; de esta manera el lector puede acercarse a los contextos de viaje más comunes de la época: desde las misiones diplomáticas a los viajes de negocios o las peregrinaciones, entre otras. También se hace hincapié en el estudio del viaje como espacio de sociabilidad y de convivencia; particularmente a través de los relatos palmeros de Bernhard von Breydenbach y de Felix Fabri en los que destaca la valoración de la convivencia entre gentes de diferentes orígenes y de distintas naciones a lo largo del camino, así como las descripciones sobre los distintos grupos culturales que poblaban Tierra Santa.

En el segundo capítulo del primer bloque se estudia en detalle un relato singular de la literatura medieval castellana: Andanças y viajes por el mundo avidos, de Pero Tafur. Aquí se tratan de forma más profunda la descripción de los diferentes otros que Tafur se encuentra a lo largo del viaje, prestando atención a cuestiones sociales, étnicas, religiosas o de género entre otras. Andanças y viajes es un libro especial en el contexto de la literatura medieval ibérica y contrasta con los relatos de peregrinaje, diplomáticos o mercantiles vistos al comienzo del bloque.

En el tercer capitulo se recorre el camino inverso al de los viajes de Tafur, de Breydenbach o de Fabri, en este caso a través del análisis de tres viajes protagonizados por centroeuropeos en la Península Ibérica. Empezando con el relato más corto y antiguo de los tres: Reisen nach der Ritterschaft del caballero suabo Georg von Ehingen, un relato clásico de caballería. Continuando con las dos versiones del viaje diplomático del barón bohemio Leo von Rožmital, escritas una en checo por Vaklav 
Šašek y otra en alemán por Gabriel Tetzel. Y finalizando con un texto más conocido: El Itinerario de Hieronymus Münzer, un patricio adinerado de la ciudad imperial de Núremberg. El texto de Münzer, donde se muestra un interés particular por la incipiente expansión portuguesa y castellana, supone un punto de conexión inmejorable con la segunda parte del trabajo: El viaje en el mundo atlántico y la visión del otro a comienzos de la "modernidad colonial".

El segundo bloque está como el anterior dividido en varias secciones. Los dos primeros capítulos, dedicados a lo monstruoso y lo fantástico uno y a la conquista de las Islas Canarias (que podrían considerarse por su contenido como puramente medievales) forman un cemento lógico en la estructura del trabajo y unen dos espacios: La literatura de viajes mediterránea medieval y la literatura de viajes atlántica moderna.

Tras analizar la importancia de lo maravilloso en el contexto del viaje y después de conquistar Canarias con Jean de Béthencourt y Gadifer la Salle, el tercer capítulo del bloque está dedicado la relación entre el mapa y el relato de viajes así como al estudio del peso de lo empírico, lo fantástico y lo simbólico en la recepción de viaje. Usando como ejemplo el mapa de América Americae sive quartae orbis partis nova et exactissima descriptio del cartógrafo Diego Gutiérrez se presentan varios elementos simbólicos fundamentales en la alteridad americana: los gigantes o patagones y los caníbales.

Para ilustrar la importancia de ambas figuras, representadas en multitud de mapas de América entre los siglos XV y XVIII, son analizadas a modo de microhistorias algunos episodios ilustrativos de la literatura de viajes moderna: el encuentro de la tripulación de Fernando de Magallanes con Patagones, descrito en Relazione del primo viaggio intorno al mondo de Antonio Piagafetta y la carta de Giovanni da Verrazzano al Rey Francisco I de Francia.

El cuarto y último capítulo de este bloque se titula "la invención de América y el descubrimiento del otro", para comenzar se presta atención a la problemática generada en torno a la identidad americana asociada al descubrimiento. A continuación es analizado el llamado "descubrimiento de América", poniendo especial énfasis en $E l$ Diario de a Bordo del primer viaje colombino y en las primerísimas descripciones de los nativos del nuevo mundo cuando este no era aún considerado un mundo nuevo. En este último bloque son descritos con más detalle los debates de índole historiográfica e ideológica que se han dado en torno al descubrimiento y en torno a la figura del viajero genovés, posiblemente el personaje más controvertido de todos los presentados en esta tesis. 